

\title{
MYTH AND EDUCATION
}

\begin{abstract}
In $21^{\text {st }}$ century early decades it is not senseless to relate the terms 'myth' and 'pedagogy', especially on the basis that myth is essentially a narrative act. It is highlighted that narrative is -must be- a constituent factor in all the stages the progressive and not always successful building of the human being passes through in this world. Despite the bodily senses and the inherent attributes of the human condition, without narrative it is not possible to reach fully human status, which consists mainly in the ability each one has to turn himself/herself into words, and to build and turn into words the reality from the languages transmitted by those identified as 'host structures' (co-offspring, co-residency, co-transcendence, and co-mediation), whose primary mission is to provide languages for the human being in every season of his/her biographical journey, from birth to death.
\end{abstract}

Keywords: pedagogy, myth, culture, language, group.

\section{Mythe et Pédagogie}

\section{Résumé}

Au cours des premières décennies du XXIème siècle, établir un lien entre les mots 'mythe' et 'pédagogie' ne semblent pas hors de propos, plus spécialement si l'on part du principe que le mythe est fondamentalement un récit en action. Il faut souligner le fait que, depuis la naissance jusqu'à la mort, le fait de raconter est —ou devrait être — un facteur constituant de toutes les étapes traversées par l'être humain pour sa progression et son développement dans le monde qui ne se voit toutefois pas toujours couronné par un succès. En dépit de disposer des sens corporels et des attributs inhérents à la condition humaine, sans le récit il n'est pas possible que l'homme ou la femme concrets 
puissent atteindre pleinement le stade d'humains. Ceci consiste surtout dans la capacité d'enrichir son propre vocabulaire et de construire et de donner des noms à la réalité à partir des langages qui nous sont transmis par ceux que je désigne sous l'expression de 'structures d'accueil' (co-descendance, corésidence, co-transcendance et co-médiation), dont la mission fondamentale consiste à offrir des langages à l'être humain lors de toutes les étapes de son périple biographique depuis sa naissance jusqu’à sa mort.

Mots clés: pédagogie, mythe, culture, langage, collectif.

\section{Mito e Pedagogia}

\section{Resumo}

Nestas primeiras décadas do século XXI pôr em relação os vocábulos «mito» e «pedagogia» não é nenhum desproposito, especialmente quando se parte da base que o mito fundamentalmente é narração em ocorrência. Tem de salientar-se o fato que, desde o nascimento até a morte, o narrar é -deveria ser- um fator constituinte em todas as etapas pelas que cruza a progressiva e não sempre exitosa edificação do ser humano neste mundo. Embora dispuser dos sentidos corporais e dos atributos inerentes à condição humana, sem narração não tem possibilidade que o homem ou a mulher, concretos, atinjam em plenitude o estatuto de humanos. Aquele consiste sobre tudo na capacidade de se encorajar em falar a se mesmo e de construir e encorajar a realidade a partir das linguagens que lhe são transmitidas pelas que se designam com a expressão «estruturas de acolhida» (co - descendência, co residência, co - transcendência e co - mediação), cuja missão fundamental consiste em oferecer linguagens ao ser humano em todas as estações do seu percurso biográfico desde o nascimento até a morte.

Palavras chave: pedagoga, mito, cultura, linguagem coletivo. 


\section{Introducción}

Desde los presocráticos griegos del siglo VII a. C. hasta el presente $-\mathrm{y}$ sobre todo en momentos en que lo ilustrado (concepto) parecía triunfar definitivamente sobre lo romántico (imagen)—, el mito ha sido objeto de innumerables discusiones y tomas de posición. Ahora mismo, atravesando como estamos un período histórico caracterizado por una cierta romantización, el recurso al mito se hace a plena luz, mientras que en épocas de signo más ilustrado este no se había esfumado, como propagaban los adalides de la completa racionalización de lo humano, sino que actuaba de incógnito, subterráneamente.

En estas primeras décadas del siglo XXI poner en relación los vocablos 'mito' y 'pedagogía' no es ningún despropósito, especialmente si se parte de la base que el mito fundamentalmente es narración en acto. Ha de subrayarse el hecho que, desde el nacimiento hasta la muerte, el narrar es — debería ser- un factor constituyente en todas las etapas por las que atraviesa la progresiva y no siempre exitosa edificación del ser humano en este mundo. A pesar de disponer de los sentidos corporales y de los atributos inherentes a la condición humana, sin narración no hay posibilidad de que el hombre o la mujer concretos alcancen en plenitud el estatuto de humanos. Este consiste sobre todo en la capacidad de empalabrarse a sí mismo y de construir y empalabrar la realidad a partir de los lenguajes que le son transmitidos por las que designo con la expresión 'estructuras de acogida' (codescendencia, corresidencia, cotrascendencia y comediación), cuya misión fundamental consiste en ofrecer lenguajes al ser humano en todas las estaciones de su periplo biográfico desde el nacimiento hasta la muerte. Por consiguiente no puede causar extrañeza que, desde hace más de cien años y a partir de premisas ideológicas y metodológicas muy diferentes e incluso contrapuestas, la narración haya suscitado, para bien y para mal, el vivo interés de filósofos, antropólogos, teólogos, psicólogos, etc. En efecto, se ha comprobado que sin adecuados procesos narrativos no es posible que los seres humanos, que son sin excepción posible actores y actrices que actúan (representan y se representan) sobre el escenario del gran teatro del mundo, consigan aprender y desarrollar de manera adecuada el oficio de hombre o mujer en el seno de la tradición cultural en la que se encuentran ubicados. Despertar el interés por lo narrativo implica casi automáticamente referirse a los universos míticos y a su función en la existencia humana. 


\section{Debate en torno a 'lo mítico'}

Antes de entrar en materia es imprescindible que haga una acotación metodológica. Es fundamental la distinción entre ‘lo mítico’ y las articulaciones histórico-culturales de ello, esto es, las distintas narraciones míticas concretas, que son articulaciones histórico-culturales, siempre deficientes, de 'lo mítico'. En el ser humano 'lo mítico' — lo mismo puede afirmarse de 'lo político', 'lo simbólico' o 'lo religioso'- pertenece al ámbito de lo estructural, es decir, de lo que es común a todos los seres humanos sin consideraciones de sexo, cultura, formación o lengua. Se trata, por consiguiente, de un universal que, en sí mismo, es ahistórico, imposible de articularlo exhaustivamente en términos culturales, sociales o biográficos, cuya existencia, por consiguiente, se infiere a partir de los comportamientos y actitudes históricas de hombres y mujeres de todos los tiempos y latitudes. Lo estructural muestra la igualdad radical, absoluta, de todos los seres humanos, mientras que lo histórico pone de manifiesto sus diferencias, siempre relativas, superables históricas y con matices de carácter biográfico. 'Igualdad estructural' y 'diferencias culturales o históricas' establecen, a mi entender, el campo antropológico de lo humano que, como es obvio, a lo largo y ancho de la andadura histórica de la humanidad ha provocado — y provoca — toda suerte de conflictos y desencuentros.

Lo estructural en sí mismo — en este caso 'lo mítico' - es inaccesible, inarticulable. Porque para el ser humano no hay ninguna posibilidad extracultural, 'lo mítico' se torna mediatamente accesible, es decir, en algo para nosotros, mediante empalabramientos culturales a tenor de las variadas coyunturas, peripecias y contextos por los que, individual y colectivamente, atraviesa la existencia humana. Los temas míticos como, por ejemplo, Antígona, Heracles, Fausto o Isis, en la diversidad de espacios y tiempos, han sido empalabrados muy diferentemente, de tal manera que, a través de ellos, es perceptible la continuidad del tema ('lo mítico') en los cambios que se han producido en los contextos sociales, religiosos o políticos. Eso viene a corroborar la idea que la contraposición entre continuidad y cambio es de capital importancia para cualquier aproximación antropológica realista porque responde a lo que, de hecho, es el ser humano concreto.

Desde la antigüedad griega hasta nuestros días el mito se ha visto envuelto en innumerables polémicas, descalificaciones y rotundas declaraciones que proclamaban que el ser humano ya había superado definitivamente la fase mítica de la humanidad — que era en realidad un estadio infantil, prehumano, 
oscuro y casi irracional (supuesto paso del «mythos» al «logos») — y se había establecido en el campo luminoso y trasparente de la razón sin necesidad de recurrir a fábulas engañosas y supersticiones grotescas para dar razón de su presencia en el mundo. A partir de lo que podríamos llamar la tesitura clásica de la Ilustración, el «logos» equivalía a la verdad y el «mythos» a la falsedad, al error y a la minoría de edad - a menudo culpable — de la humanidad (Kant). En la actualidad estas ideas en torno al mito aún se detectan bastante fácilmente en amplios sectores de los medios de comunicación, ámbitos universitarios, escuelas de magisterio, adictos incondicionales de las "ciencias duras", etcétera. Sin embargo en la vida cotidiana de individuos y grupos humanos se continúa, consciente o inconscientemente, recurriendo a lo mítico, mitificando —o tal vez mejor mistificando-incluso el instrumental, por ejemplo, la misma razón que, según se afirmaba, era la encargada de proceder a la destrucción de lo mítico ('desmitización') con la finalidad de implantar, casi como si de una cruzada se tratara, el benéfico imperio del «lógos» en todos los ámbitos de la existencia humana. Pero no cabe duda que, de mil maneras, en contextos sociales y culturales muy variados, los grandes temas y personajes míticos (Antígona, Prometeo, Ícaro, Ulises, etc.) continúan siendo nuestros coetáneos, que nos ofrecen narrativa y teatralmente algunas formas, más o menos plásticas, de dar razón de lo que en sí mismo se encuentra más allá o más acá de la comprensión y la experiencia humanas, para intentar hacer frente al abrumador absolutismo de la realidad (Blumenberg, 2003), para instituir, siempre provisionalmente, praxis de dominación de la contingencia (Lübbe), para intentar armonizar en nuestro diario vivir y convivir los lenguajes de los efectos con los de los afectos en un equilibrio siempre inestable y necesitado de continuas contextualizaciones.

\section{Narración y procesos educativos}

En los procesos educativos la narración tendría que ser una de las piedras angulares, la herramienta propicia para poner en marcha transmisiones y aprendizajes efectivos y afectivos con la finalidad de que infantes y adolescentes adquiriesen los lenguajes que les permitieran construir con sentido, en medio de un mundo que siempre tendrá tendencias caotizantes, su espacio y su tiempo —denominados por Maurice Merleau-Ponty (1975) el espacio y el tiempo antropológicos - y, de esta manera, habitar en un mundo que así habría superado, al menos en parte, su opacidad natural. Los lenguajes de los afectos — en el fondo la sabiduría («sapientia») — no debería excluir los lenguajes de los efectos —en el fondo la ciencia («scientia») — , sino que ambos se hallan —deberían hallarse_ íntimamente coimplicados. En realidad los intentos 
de reducir en exclusiva el conjunto de la existencia humana a 'lo mítico' o a 'lo lógico', desde perspectivas políticas, religiosas, sociales o económicas, tal como lo ponen de manifiesto innombrables ejemplos del pasado y del presente, acaban en lo mismo: actitudes y discursos totalitarios en los que la contraposición creativa entre imagen y concepto se anula por completo, y se intentan instaurar en el campo de la vida pública y privada formas de pensamiento y acción — sin excluir el ámbito de los sentimientos — con una inexorable y policíaca "regulación ortodoxa" (Deconchy), caracterizada por lo común por una enorme pobreza léxica que, con frecuencia, se resuelve mediante el lenguaje de la violencia, que es, en realidad, un no-lenguaje, una terrible destrucción del poliglotismo y polifonismo de la palabra humana.

Hombres y mujeres, más allá de las evidentes diferencias históricas y culturales, somos seres estructuralmente logomíticos que, en la variedad de espacios y tiempos, de geografías e historias, de temperamentos y preferencias, expresamos míticamente lo lógico y lógicamente lo mítico, o, dicho de otro modo, en lo mítico siempre hay «lógos» y en el «lógos» siempre se hace presente lo mítico. En las diurnidades de lo lógico, de una manera u otra, se encuentran las nocturnidades de lo mítico, y en este, aunque parezca imposible, está presente lo diurno de la lógica, de la conceptualización discursiva. De hecho la tradición ha calificado al ser humano de «coincidentia» o «complexio oppositorum», esto es, de un ser que posee múltiples facetas, no siempre fácilmente conciliables entre sí, que exigen, cada una de ellas, un lenguaje apropiado para expresarse debidamente, y que es, por consiguiente, inaplicable para empalabrar las otras facetas (Paz, 1956). Porque somos seres polifacéticos, hombres y mujeres somos seres polifónicos o, dicho de otra manera, los humanos, tengamos o no conciencia de ello, porque no podemos abandonar las gramáticas, vivimos y morimos en el seno de la palabra humana, cuyos numerosos registros se extienden desde la ética hasta la estética, desde lo lógico hasta lo imaginario, desde el deseo hasta lo fáctico; porque somos seres finitos y contingentes los humanos somos seres deseantes, y es evidente que esta capacidad constitutiva del ser humano da razón de su insuperable ambigüedad. El deseo, ya sea en forma de nostalgia o de utopía, se articula preponderantemente mediante la plasticidad y flexibilidad de las narraciones míticas. Aquí deberíamos introducir la compleja problemática en torno al símbolo o, lo que viene a ser lo mismo, la insuperable relación constitutiva de hombres y mujeres con 'lo ausente' pasado y futuro que, de alguna manera, se tornan activos e influyentes — en ocasiones trágicamente activos e influyentes - en el 'presente del presente'. Una de las características más significativas y, al mismo tiempo, más inquietantes del momento presente es, 
tal vez como consecuencia de la crisis pedagógica y gramatical que sufrimos, la irrelevancia creciente del conjunto de transmisiones que, desde el nacimiento hasta la muerte, nos permiten la articulación —-Mircea Eliade (1972) y Peter Berger utilizan el término 'cosmización'- de nuestra existencia, a pesar de la presencia y actividad constante de múltiples e inquietantes presencias de la negatividad, que tienden a provocar la desestructuración de lo humano. Todas las culturas humanas, a pesar de las grandes diferencias históricas que hay entre ellas, han percibido con singular lucidez que los seres humanos constantemente nos movemos entre dos movimientos antitéticos y aparentemente irreconciliables entre sí: 1) paso del cosmos al caos y 2) paso del caos al cosmos.

\section{Funciones del mito}

1. «Función epistémica». Se trata de precisar en qué consiste el trabajo del mito como modo de conocimiento y de exposición, y de qué manera su contribución se diferencia de las otras formas de conocimiento. El mito posee los rasgos de una memoria genealógica que traza narrativamente, no explicativamente, como a menudo ha sucedido, un esbozo del pasado del mundo y del origen de un determinado grupo humano. Describe el mundo presente poniendo en juego las fuerzas y las leyes que le dieron consistencia en los orígenes y continúan sosteniéndole en la actualidad. Como descripción del mundo el mito no es una simple copia mecánica de este, sino una articulación y sistematización, sobre todo en términos alusivos, que permite la orientación de los que viven en él. Como agente interpretador del mundo el mito es al mismo tiempo un engendrador y uno de los factores fundamentales para la autocomprensión del ser humano que habita en él.

2. «Función social». La gran mayoría de las teorías sobre el mito han señalado que su función social era fundamental por cuanto se refiere a la genealogía común de quienes comparten no solo una misma cultura, sino el hecho de pertenecer todos, sin distinción de sexo, nación, cultura o religión, a la misma y única humanidad, con los interrogantes fundacionales que la acechan sin cesar. La etnología, las ciencias de las religiones y las teorías de la cultura han subrayado la continua presencia del mito en la vida cotidiana de todos los grupos humanos y pueblos y, al mismo tiempo, han puesto de relieve las peculiaridades de la memoria mítica de cada grupo humano en relación con las formas de pensamiento seculares y científicas. Hace ya algunos años la Cambridge School of Anthropology colocó en el centro de sus investigaciones la conexión 
del mito y del ritual religioso. Es harto evidente que aquí deberíamos referirnos con cierto detalle a la cuestión de la «cultualidad» como categoría antropológica del ser humano. Creo que toda buena pedagogía ha de tener muy en cuenta, a pesar del descrédito que experimenta en la actualidad, lo cultual como forma muy elocuente y teatralizada de la presencia —o, sin duda, mejor, de la representación — del ser humano en su vida cotidiana. Desde el punto de vista de esta concepción, el mito es la contraparte lingüística de una acción cultual, el cual (el mito narrado) resulta activo y eficaz a partir la acción cultual, sea esta pública o privada. Para un determinado grupo humano las funciones del mito se pueden concretar, por un lado, en una orientación común en los caminos del mundo, en la definición y fundamentación de costumbres y autoridades y, por el otro, en la identidad colectiva hacia afuera del grupo y en su legitimación hacia adentro. La memoria mítica como aspecto fundamental de la llamada 'memoria colectiva o cultural' asocia en un todo - tal vez incoherente lógicamente pero apropiado y realista míticamente- el presente del grupo humano con los acontecimientos fundacionales; un todo que asegura y legitima la situación presente del grupo y le ofrece garantías, a pesar de la inquietante presencia del mal y la muerte ante el futuro. Porque se posee una clara conciencia de que el paso del tiempo implica envejecimiento e, incluso, envilecimiento, es imprescindible con periodicidad restaurar el mundo en su primigenia belleza y orden, sobre todo en la fiesta de año nuevo.

3. «Función antropológica». Es incuestionable que la función social que ejerce el mito se encuentra vinculada con algunos aspectos antropológicos especialmente relevantes. El mito es una forma de plantear narrativamente las cuestiones existenciales que asedian a los humanos desde el nacimiento hasta la muerte. Su significación se explicita, en parte, como fase del convertirse en miembro del grupo (por ejemplo mediante los procesos de iniciación) y, en parte también, como una cuasi-filosofía de la historia compartida - más o menos reflexiva y emotivamente- por quienes forman parte de una determinada comunidad humana. Es harto evidente que, en relación con lo que acabo de señalar, tendríamos que proceder a discutir las determinantes relaciones entre los explícitos y los implícitos en la existencia de individuos y grupos humanos. De ahí se derivaría el debate en torno a la memoria colectiva o cultural que, consciente o inconscientemente, siempre es determinante para la existencia humana.

En el siglo XX algunos investigadores han interpretado el mito como una etapa en el camino hacia la autoafirmación humana. Así, por ejemplo, 
Theodor W. Adorno y Max Horkheimer en la obra fundamental Dialektik der Aufklärung (1944), ven en el mito una preforma de la Ilustración, un paso hacia la autoafirmación del sujeto humano por mediación de la sujeción y el espolio de la naturaleza. En su libro Arbeit am Mythos Hans Blumenberg mantiene una tesis muy parecida: el mito ha servido para depotenciar las angustias arcaicas del ser humano. Con la ayuda de denominaciones, articulaciones y estructuraciones, intenta someter $\mathrm{o}$, al menos, disminuir lo que Blumenberg designa con la expresión 'absolutismo de la realidad'. En esta manera de ver las cosas la función existencial del mito se vincula directamente con su trabajo cognitivo para tener, aunque sea tentativamente, acceso al misterio del mundo. Aquí se manifiesta la tensa relación entre angustia y búsqueda de seguridad como impulso rector del deseo de conocer, que afecta, aunque sea de manera mediata, la determinación de las relaciones entre mito y filosofía. El interrogante que se impone es: ¿en qué medida el mito transformado en logos no se encuentra determinado por el mismo impulso humano que puso en circulación el mito? No se pueden olvidar las contribuciones de otros investigadores que han puesto todo el énfasis en la negatividad humana, de la que el mito sería al mismo tiempo la experiencia y la superación. Por ejemplo Paul Ricoeur en su estudio sobre la confrontación del mito con el mal, u otros autores (Burkert, Vernant y Girard), que ven el mito no solo como un medio de lucha contra la destrucción y el poder de las llamadas por Walter Burkert, gegenpotenzen, 'contrapotencias', sino también un medio apto para la integración de los diversos niveles del ser humano. En un sentido más amplio Lévi-Strauss (1987) considera que el trabajo realizado por el mito consiste especialmente en la mediación, siempre in fieri, entre naturaleza y cultura. Aquí, evidentemente, se insinúa una temática antropológica de dimensiones inmensas y con resultados siempre discutibles que no podemos abordar en esta exposición.

\section{Los centros de las narraciones míticas}

La protología y la escatología, el origen y el término, han sido en todas las culturas los campos en donde la presencia y el trabajo de la disposición mítica del ser humano se han mostrado más efectivos y creadores. Aunque sea imprescindible para la existencia humana la historia no basta para expresar la totalidad de lo humano. $\mathrm{O}$, diciéndolo de otro modo, no pudiendo dejar de ser histórico, el ser humano es más que el desenvolvimiento material de sus peripecias históricas, de sus múltiples y, a menudo, desconcertantes 'historias'. Siempre, lo sepa o no, lo quiera o no, tiene necesidad de lo pretemporal y de lo postemporal: el antes del tiempo y el después del tiempo, las imágenes de 
la plenitud inicial y las de la realización final. En muchas culturas humanas los orígenes - y eso es especialmente urgente en una 'civilización del olvido' como la que impera en la actualidad - ofrecen la clave de lo que es el núcleo de la realidad. Son auténticos creadores de mundos. En relación con los orígenes se articula (por ejemplo literaria o musicalmente) lo que se relaciona con el principio del trayecto histórico de la existencia humana; un comenzar a existir que, al mismo tiempo, implica una remisión al término final, ya sea este de carácter mortal o inmortal. Por eso, vistas las cosas míticamente, los orígenes son indisociables de su polo antitético: el término final, esto es, la realización plena o la aniquilación también plena de lo que antaño tuvo tiempo que, hablando plásticamente, ya ha alcanzado el no tiempo, ya sea en la forma de eternidad o de nada. Los mitos de origen (y entre los mitos de origen deben incluirse también los mitos escatológicos, porque siempre se trata, míticamente hablando, del origen, aunque sea el origen del término) han sido tan decisivos en el trayecto temporal del ser humano porque en ellos se busca la respuesta a los interrogantes genealógicos decisivos: de dónde vengo, hacia dónde me encamino, qué sentido tiene la existencia, por qué el mal, etc. En relación con el mito tal vez pueda afirmarse que la pregunta de Leibniz: ¿por qué existe algo en lugar de nada?, también es una cuestión decisiva en relación con los universos míticos, de aquí la importancia excepcional de los mitos de origen (incluso algunos autores reducen los mitos escatológicos al mito de origen). En los universos míticos otra cuestión que suele encontrarse íntimamente vinculada con la que he indicado hace un momento: ¿por qué lo que ha alcanzado la existencia ha de dejar de existir? Además los mitos de origen son los que establecen de manera cualificada y sancionada sacralmente los límites, los ritmos, las temporalizaciones, las especializaciones, los modos paradigmáticos de relación, etc., de todo lo que existe en el mundo como relacionado de la manera que sea con el ser humano. Diciéndolo de otra manera: en los orígenes el tiempo "nace" y se convierte en una realidad humanamente aprehensible, porque en los orígenes del tiempo se encuentra la división o, lo que es lo mismo, la posibilidad de cuantificación y establecimiento de secuencias. A partir de la eternidad o, en lenguaje mítico, a partir del "tiempo divino", es decir, del "no-tiempo humano", se constituye el tiempo específico de aquel que ha irrumpido en la realidad por medio de la división de la unidad compacta, perfecta y autosuficiente, original, esto es, del hombre. Una cuestión que ahora tenemos que dejar entre paréntesis es en qué medida los mitos son proyectos para la abolición del tiempo en el tiempo, es decir, en qué medida los mitos son "artefactos gnósticos". El mito también se propone dar razón narrativamente del hombre como ser desgarrado, ambiguo, en búsqueda constante de la 
unidad perdida, esto es, del paraíso perdido. La dolorosa y omnipresente fractura que se encuentra en el centro del mismo hecho de vivir con la angustia correspondiente es una de las grandes temáticas recurrentes en los universos míticos. La irrupción de la muerte, de la enfermedad, de la irreconciliación impuesta por las insatisfacciones del deseo, del mal, de la guerra, etc., en la convivencia (o la malvivencia) de los mortales, es decir, todo lo que tiene algo que ver con la fragilidad radical del ser humano se articula en forma de teodiceas prácticas en las narraciones míticas. Narraciones que, al menos inicialmente, no pretenden ser explicaciones en un sentido meramente causal, sino que más bien pretenden ser como viáticos, en los que la empatía colectiva es un dato muy importante para poder continuar el camino de la vida con una cierta reducción de las dosis de angustia y de inseguridad que siempre contiene. Por eso los mitos, que nunca son elucubraciones teóricas, pueden ser considerados como "praxis de dominación de la contingencia", apropiándome de una fórmula que Hermann Lübbe aplica a la religión. Debería tenerse en cuenta que el sometimiento a la contingencia constituye el 'estado natural', insuperable y promotor de profundo desasosiego e, incluso, de patologías severas, de hombres y mujeres.

Me he referido a la cualidad teodiceica que suelen poseer las narraciones míticas. Eso significa que el mito, como la misma tradición con la que comparte muchos elementos, es para la vida humana y no la vida humana para el mito (o para la tradición). A partir de aquí puede hacerse una observación que me parece que, desde una perspectiva pedagógica, posee un gran interés: se trata de la plasticidad o flexibilidad que es propia del mito. El mito se hace eco de un aspecto fundamental y, muy a menudo, doloroso de la existencia humana, y es que todo ser humano se encuentra íntimamente desgarrado entre lo que podríamos denominar su disposición estructural (lo que podríamos llamar 'lo mítico' o 'lo simbólico'), que comparte con todos los demás representantes de la especie humana, y la situación histórica, que es característica y peculiar de cada hombre y de cada colectividad en concreto. La plasticidad de los mitos a la que me he referido intenta dar razón de esta situación tan característica del ser humano: concreción de lo mismo (esto es de los interrogantes genealógicos fundamentales), en función de las variaciones histórico-culturales que son inherentes al hecho de vivir y morir como mujer o como hombre en un determinado lugar, haciendo uso de una lengua con unos recursos expresivos concretos, con un imaginario colectivo característico. Expresándolo de otra manera: la plasticidad de los mitos pone en relieve que para el ser humano no hay posibilidad extracultural. Los mitos concretos pueden ser considerados como variaciones o secuencias musicales 
en función de los cambios que experimenten la experiencia y la expresión del tiempo y los espacios por parte del hombre. Pero, al mismo tiempo, los elementos constitutivos de las series míticas son expresiones culturalmente diversa de lo mismo que, por regla general, puede resumirse con dos vocablos: protología y escatología.

Son muy oportunas las acotaciones que formula Christoph Jamme (1991) en relación con la masiva presencia del mito en las actuales discusiones en torno a las realizaciones culturales de tipo filosófico, estético, literario, político, religioso, etc. No puede entablarse una fructífera discusión sobre el mito si, previamente, por un lado, no se reflexiona con seriedad, abandonando los tópicos habituales, sobre las relaciones entre vida y racionalidad, entre imagen y concepto y, por el otro, si no se adquiere un conocimiento bien fundamentado de las condiciones y los prejuicios que hicieron posible el origen de la 'racionalidad clásica'. Esta es una tarea práctica propia de una escuela que quiera transmitir a infantes y adolescentes una comprensión del ser humano polifacética y polifónica. La escuela, por su misma naturaleza, tendría que ser, junto con la familia, el ámbito privilegiado en donde se adiestra eficazmente el poliglotismo de la palabra humana.

\section{Conclusión}

La actualidad de la problemática en torno al mito, me parece, es un síntoma muy elocuente del estado de revisión en que se encuentra la cultura occidental, sobre todo en relación con los procesos de transmisión que tienen lugar en el interior de esta cultura. Esta revisión compete a filósofos, antropólogos, pedagogos, críticos literarios, historiadores y también al hombre de la calle. Desde una perspectiva antropológica creo que puede afirmarse que, en el fondo, en la actualidad, estamos pagando la factura a causa del mal uso de las imágenes y los símbolos que, habitualmente, se ha hecho en la cultura occidental. Se ha pretendido o bien una total desmitización, un aniquilamiento radical del poder sanador y reconciliador de las imágenes y las narraciones, o bien, por el contrario, se ha intentado en lo concreto de la vida cotidiana la configuración de existencias míticas sin ningún aliento crítico. Tal vez hemos olvidado que hombres y mujeres somos siempre, y no podemos dejar de serlo, seres logo-míticos que necesitamos dicciones y narrativas complementarias e irreductibles las unas a las otras para expresarnos, actuar y actualizar nuestra existencia de manera polifónica y en búsqueda de una cierta armonía. 


\section{Referencias $^{1}$}

BACHELARD, G. (2013). La poética del espacio. México: Fondo de Cultura Económica.

BALANDIER, G. (1989). El desorden. La teoría del caos y las ciencias sociales. Barcelona: Gedisa.

BENJAMIN, W. (1991). 'El narrador'. BENJAMIN, W. Para una crítica de la violencia y otros ensayos. Iluminaciones IV. Madrid: Taurus. [pp. 111-134].

BLUMENBERG, H. (2003). Trabajo sobre el mito. Barcelona - Buenos Aires -México: Paidós.

BRISSON, L. (1996). Einführung in die Philosophie des Mythos. Antike, Mittel-alter und Renaissance. Darmstadt: Wissenschaftliche Buch-gesellschaft.

CAMPBELL, J. (1972). El héroe de las mil caras. Psicoanálisis del mito. México: Fondo de Cultura Económica.

Cassirer, E. (1969.) El mito del Estado. México: Fondo de Cultura Económica. (1998). Filosofía de las formas simbólicas. I: El lenguaje; II: El pensamiento mítico; III: Fenomenología del reconocimiento [3 vol.] México: Fondo de Cultura Económica.

DUCH, L. (1978). Historia y estructuras religiosas. Aportación al estudio de la fenomenología de la religión. Madrid -Barcelona: Bruño - Edebé. (2001). La educación y la crisis de la modernidad. Barcelona - Buenos Aires - México: Paidós. (2002). Mito, interpretación y cultura. Introducción a la logomítica. Barcelona: Herder. (2004). Estaciones del laberinto. Ensayos de antropología. Barcelona: Herder. (2012). Religión y comunicación. Barcelona: Fragmenta.

DUCH, L. \& CHILLÓN, A. (2014). Un ser de mediaciones. Antropología de la comunicación I. Barcelona: Herder.

DURAND, G. (2003). Mitos y sociedades. Introducción a la mitodología. Buenos Aires: Biblos.

(2005). Las estructuras antropológicas del imaginario. Introducción a la arquetipología general. México - Madrid: Fondo de Cultura Económica. (2013). De la mitocrítica al mitoanálisis. Figuras míticas y aspectos de la obra. Barcelona: Anthropos.

1 NOTA DE LOS EDITORES. En las referencias finales del artículo encontramos autores que no están citados de manera directa en el contenido del texto. Sin embargo, por tratarse de Lluís Duch, erudito y especialista en el tema de mito y educación, hemos decidido respetar el listado original de referencias que él hace al final de su artículo. 
ELIADE, M. (1972). El mito del eterno retorno. Arquetipos y repetición. Madrid -Buenos Aires: Alianza - Emecé.

FRANK, M. (2004). Dios en el exilio. Lecciones sobre la nueva mitología. Madrid: Akal.

GARCÍA-GUAL, C. (2014). Historia mínima de la mitología. México - Madrid: Colegio de México - Turner.

HÜBNER, K. (1985). Die Wahrheit des Mythos. Múnich: C. H. Beck.

ISER, W. (2005). Rutas de la interpretación. México: Fondo de Cultura Económica.

JAMME, C. (1991). Gott an "hat ein Gewand". Grenzen und Perspektiven philosophischer Mythos-Theorien der Gegenwart. Fráncfurt: Suhrkamp.

JESI, F. (1976). Mito. Barcelona: Labor.

KIRK, G. (1990). El mito. Su significado y funciones en la Antigüedad y otras culturas. Barcelona - Buenos Aires - México: Paidós.

KOLAKOWSKI, L. (1990). La presencia del mito. Madrid: Cátedra.

LÉVI-STRAUSS, C. (1987). Mito y significado. Madrid: Alianza.

MAY, R. (1992). La necesidad del mito. La influencia de los modelos culturales en el mundo contemporáneo. Barcelona: Paidós.

MERLEAU-PONTY, M. (1975). Fenomenología de la percepción. Barcelona: Península.

MOHN, J. (1998). Mythostheorien. Eine religionswissenschaftliche Untersu-chung zu Mythos und Interkulturalität. Múnich: W. Fink.

PAZ, O. (1956). El Arco y la lira. El poema, la revelación poética, poesía e historia. México - Buenos Aires: Fondo de Cultura Económica.

PRADES, J. (1998). Lo sagrado. Del mundo arcaico a la modernidad. Barcelona: Península.

REVAULT D'ALLONNES, M. (1999). Ce que l'bomme fait à l'homme. Essai sur le malpolitique. París: Gallimard.

STEINER, G. (1996). Antígonas. Una poética y una filosofía de la lectura. Barcelona: Gedisa.

URBAN, W. M. (1979). Lenguaje y realidad. La filosofía del lenguaje y los principios del simbolismo. México: Fondo de Cultura Económica. 